\title{
O IDOSO E O SEU PROCESSO GRUPAL INSTITUCIONAL NUM PROGRAMA PARA IDOSOS *
}

Locimara Ramos Kroeff ${ }^{*}$

\section{Resumo}

Este estudo objetiva descrever e explicar como os grupos se organizam, assumem papéis e sua dinâmica das relações de poder num grupo de idosos. Foram investigados oito grupos que representam a Universidade para a Terceira Idade (UNITI / UFRGS). Para análise dos grupos, utilizou-se relatos de observações seqüenciais. Verificou-se que a maioria dos sujeitos costumava reivindicar um líder mais autocrático e resistiam à liderança democrática e partilhada, mesmo quando ocorriam condições para o grupo exercer sua autonomia. Conclui-se que as pessoas desta faixa etária tendem a manter vínculos de dependência onde são mais sujeitadas do que sujeitos.

Palavras-chave: Idoso; Processo Grupal.

\section{Abstract}

This search aim to explain the organization of the groups, the importance and dinamic relationships in elderly groups. There were analised height elderly groups of University, called UNITI/UFRGS (Third Age University). The sequence observations were imployed to analyse the groups. The obtained aim has showed that all of them always are needing autocratic leadership even the group has conditions to use the autonomy, however they have seens to be hard to sharing and democratic leadering. So, the search conclues this same age elderly try to keep any dependence living, therefore they are more submited than the submiter.

Key words: Elderly, Groupal Process.

"O presente artigo esta baseado nos dados da pesquisa “O Idoso e o Processo Grupal” de L.R. Kroeff e A. Schneider, sob a orientação de Sérgio Antônio Carlos, Doutor em Serviço Social, professor do Departamento de Psicologia Social e Institucional da UFRGS, apresentada no VIIII SALÃ DE INICIAÇÃO CIENTÍFICA e V FEIRA DE INICIAÇÃO CIENTÍFICA da UFRGS, de 9 a 13 de set. de 1996, registrada no Livro de Resumos na página 304. Financiamento CNPq/PROPESP.

na página 304. Financiamento CNPq/PROPESP. UFRGS.E-mail: locirk@vortex.ufrgs.br 


\section{Introdução}

A ausência de preparação para a aposentadoria, tanto do indivíduo como da sociedade, se reflete nos programas e projetos para a terceira idade, lançados no meio social. Para homens e mulheres, a participação social fora da família exerce uma influência positiva sobre o bem estar psicofísico (Lehr, 1984). Assim estes projetos e programas, oportunizam um reengajamento social do idoso, através de novas relações. Segundo Salgado (1979), o engajamento se processa pela inter-relação do indivíduo com a sociedade à qual pertence e o desengajamento é a retirada progressiva de pessoas envelhecidas do sistema social.

Neste sentido, existe na Universidade Federal do Rio Grande do Sul (UFRGS) a Universidade para a Terceira Idade - UNITI que tem como proposta a educação permanente visando atender a população idosa e incentivar o autogerenciamento de grupos pelos próprios idosos. Entretanto, a lifelong education que pode ser traduzida como educação permanente não está restrita a nenhum período específico do curso de vida (Browning, 1995). Atualmente, a educação permanente “. . . não significa apenas uma necessidade de renovação cultural, mas também uma exigência nova de uma autonomia dinâmica dos indivíduos numa sociedade em rápida transformação." (Neri; Cachioni, 1999, p.128). Assim, através do presente estudo buscou-se investigar como se processa a reformulação do comportamento da pessoa idosa mediada pelo pequeno grupo social. No âmbito da Universidade para a Terceira Idade (UNITI) - UFRGS em Porto Alegre, existem vários grupos em funcionamento. Dada a diversidade de grupos nesta instituição, restringiu-se a presente pesquisa na investigação de sete subgrupos emergentes do grande grupo (Grupão) que representa a UNITI com o total dos seus integrantes. A dinâmica do grande grupo também foi observada perfazendo um total de oito grupos estudados. Objetivou-se descrever e explicar como os grupos se organizam, como assumem papéis e como se dá a dinâmica da relação de poder num grupo desta faixa etária.

2 Caracterização do Universo Estudado

A UNITI está vinculada ao Departamento de Psicologia Social e 
Institucional do Instituto de Psicologia da UFRGS.

A gênese para implementação da UNITI, em 1991, foi o curso de extensão denominado Atualização da Mulher: uma forma de educação permanente, realizado no segundo semestre de 1990. Atualmente, o público alvo são idosos de ambos os sexos.

Os participantes das atividades desenvolvidos pela UNITI mantêm as características que seguem:

- Mulheres (mais de 90\%) e homens (menos de 10\%), seguindo o perfil dos Programas para a Terceira Idade que mobilizam, sobretudo o público feminino, sendo que "a participação masculina raramente ultrapassa os 10\%" (Debert, 1994, p.35).

- A faixa etária predominante dos participantes fica entre os 60 e 75 anos, sendo, a maioria, residentes em Porto Alegre. Quanto à escolaridade apresenta maior número de sujeitos com segundo e terceiro grau.

A rotina básica da UNITI consiste em reuniões semanais com todos os seus participantes, variando de 90 a 150 integrantes conforme ano de ingresso, e atividades em subgrupos: oficinas ou grupos de interesses. Nos encontros semanais são realizados palestras e painéis sobre temas de interesse do grupo. Tal grupo funciona como um "pólo irradiador" de onde derivam os subgrupos.

Os subgrupos diferenciam-se pelo interesse central de seus participantes. As oficinas de desenvolvimento interpessoal voltam-se primordialmente para o próprio sujeito na relação com os seus pares, enquanto os grupos de interesses demonstram também um envolvimento com as questões comunitárias, funcionando como elementos multiplicadores. Pode-se diferenciar tais grupos conforme Lewin apud Hagemann (1977, p.47), classifica: "Psico-grupo: centrado em si mesmo - objetivo: próprio crescimento e Sócio-grupo: voltado para a realização de tarefas." Assim, pode-se definir na UNITI os grupos de interesse como sócio-grupo e os grupos de desenvolvimento interpessoal como psico-grupo. Estes subgrupos têm encontros periódicos (uma vez por semana), sistemáticos e com dia e hora pré-determinados. Os grupos de desenvolvimento interpessoal são coordenados por um(a) psicólogo(a), bolsista ou estagiário(a) 
de Psicologia. Os grupos de interesse são coordenados pelos próprios usuários dentro da ideologia da autogestão promovida pela UNITI, sendo constituídos autonomamente pelos seus participantes.

\section{Método}

Em cada grupo estiveram presentes um observador além do coordenador do mesmo, perfazendo um total de 130 observações distribuídas diferencialmente entre os grupos. Utilizaram-se relatos de observações seqüenciais de observadores (estagiários de Psicologia Escolar, alunos da disciplina de Dinâmica de Grupo e bolsistas de pesquisa) em grupos de diferentes semestres da UNITI, de 1992 a 1995. Portanto, as observações e relatos, coletados nos grupos, foram retirados em diversos momentos do processo evolutivo da UNITI, trazendo um viés temporalidade, além do viés de aferição. Foram anotadas as situações ou tarefas desenvolvidas e os diálogos estabelecidos. Alguns observadores realizaram uma análise mais científica permitindo uma revisão dessas na presente pesquisa. Entretanto, apesar dos diferentes estilos dos relatos e análises, pontos em comum e generalidades observadas nos grupos estudados contribuíram para o reforço das conclusões.

Em Severino (1989, p.238) buscou-se “. . . as diretrizes para leitura, análise temática e interpretação de texto.” e em Bardin (1979, p.225). “. . a a elaboração de categorias". As categorias emergentes da análise foram: identidade, papéis sociais, participação no grupo, produção de grupo, organização, tarefas e poder.

No relato a seguir, o anonimato dos grupos foi preservado ocultandose algumas referências que pudessem identificar diretamente os grupos. Devido a este procedimento algumas ações e identificações nos grupos não ficam esclarecidas, privilegiando-se a descrição das formas de relações nos grupos. 4 Grupos de Desenvolvimento Interpessoal

\subsection{Grupo 1}

Este grupo contava com dois coordenadores (um homem e uma mulher) e um total de 20 integrantes. Os coordenadores deste grupo utilizavam a definição de coordenador "disparador" que tem em vista "disparar" os mem- 
bros do grupo para que eles ocupem, também, este lugar de coordenação (coordenar). $\mathrm{O}$ coordenador disparador entende que, assim como existe um saber que lhe é dado pelo grupo, existe um saber de cada membro (Vidal, 1986) apud Baremblith (1992). Desta forma, este lugar de coordenador era um espaço a ser compartilhado com todas as pessoas que participassem deste grupo. Logo, esta posição poderia ser ocupada por qualquer indivíduo do grupo, pois pressupõe um saber a cada sujeito.

Percebeu-se nos depoimentos de muitos participantes, como os citados abaixo, um processo de mudança e reformulação pessoal devido à interação grupal:

“. . . percebi a interação do grupo a partir do segundo semestre junto com o grupo ....",

“. . . pude expressar meu pensamento com inteira liberdade, o que nem sempre consigo, pois sou taxada de excêntrica, mudei meu modo de vida e de pensar, não mais calar para não se incomodar, nos grupos eu aprendi a dizer não ....".

“. . . a reação que eu senti, eu sinto muita força, procurando viver cada vez melhor..."

Na trajetória do grupo, observou-se mudanças de comportamentos e reformulações de valores nos componentes, entretanto, também se constatou que o movimento do grupo foi no sentido de demandar o saber aos coordenadores. Terra ; Silva (1992), identificaram uma tendência do grupo em eleger um líder, de colocar em algum lugar um suposto saber sobre si e sobre as coisas. Aqui se notou que, apesar dos coordenadores adotarem uma postura "laisser faire" (Pichón, 1986), os integrantes resistiram a este aprendizado novo de se relacionar nos grupos e demandaram por um líder mais autoritário.

\subsection{Grupo 2}

O grupo estava constituído por doze sujeitos e uma coordenadora que objetivou como tema de desenvolvimento deste grupo um estudo sobre a autogestão.

Os dados da pesquisa realizada por Medina (1992), indicaram que 
para os doze sujeitos analisados a autogestão é sempre individual, o poder está institucionalizado na própria pessoa, e com relação ao grupo o poder continua centrado no dirigente do mesmo. Apesar de ter sido oportunizada a autonomia no grupo, eles, em parte, não conseguiram se desprender da função do coordenador, exigindo a presença de coordenadores que alguns denominavam professores.

Baremblith (1992), coloca a autogestão como sinônimo da auto-organização que ocorre quando a comunidade se articula e se institucionaliza para construir os dispositivos necessários à produção ou conseguir os recursos necessários para o melhoramento de sua vida. Todavia, no que concerne ao entendimento da autogestão, entendeu-se que os sujeitos do grupo investigado não perceberam a autogestão em grupo.

Uma das dificuldades para que se dê uma autogestão é o não desvelamento do poder que impede a percepção da hierarquia dentro do grupo. Por esta percepção - se dar conta - é possível romper com a hierarquia dentro do grupo chegando à autogestão. Tomar consciência das relações de poder é um dos primeiros passos para os grupos de autogestão funcionarem integralmente. Portanto, apesar da coordenação deste grupo ter sido caracterizada, basicamente, como uma liderança democrática, o grupo apresentou dificuldades para se desvelar da autoridade do coordenador, prejudicando, conseqüentemente, o exercício da autogestão.

\subsection{Grupo 3}

Neste grupo havia uma coordenadora e 25 participantes. A coordenadora se utilizava de técnicas de relaxamento para passar o que estava pensando: Põe a música: e segue falando: "O corpo está relaxado, quero pensar na minha vida, numa emoção, numa pessoa; num momento . . esta emoção, paixão, me faz queixosa? Eu só me queixo. Neste sentimento, nesta emoção, eu me envolvo, mas qual é o meu papel”. . . "Mas eu sou violento?, Onde eu coloco o meu afeto; as perdas; eu perdi coisas, mas tem coisas para amar, eu preciso ter forças, eu estou sentindo um sentimento agradável de querer e poder mudar." Notou-se que a coordenadora sugestionou um modelo para pensar em sentimentos. Assim, o pensamento do grupo deveria entrar em sintonia 
com o da coordenadora. Provavelmente, as pessoas que se identificaram com os pensamentos verbalizados pela coordenadora envolveram-se mais emocionalmente com a atividade, pois alguns participantes choravam quando prestavam depoimento sobre o seu sentimento na atividade.

Percebeu-se que a coordenadora fazia algumas intervenções indutivas esperando determinada resposta. Ela também promovia a comunicação dos integrantes do grupo estimulando a colocação de depoimentos divergentes e diferentes, proporcionando oportunidades para os integrantes intervirem nas colocações do colega. Ao final de cada encontro do grupo, em geral, ocorria a avaliação do trabalho através de questões como: "O que ficou de hoje como sentimento, o que acrescentou?"

Em decisões no grupo a coordenadora permitia que o grupo decidisse, porém colocava a sua opinião anteriormente: "Quem não trouxe (o material solicitado), não poderá trabalhar, com pedacinhos não adianta”. Dizia que não achava justo que quem não trouxesse o material ficasse observando, mas que iria consultar o grupo. Por fim, as pessoas que não trouxeram material saíram, pois o grupo concordou com a opinião explicitada pela coordenadora. Supõe-se que com o acatamento do grupo, entrando em acordo com o pensamento da coordenação, é evitado o conflito, bem como a ansiedade que tal situação pode provocar.

O grupo acima também correspondeu, na sua dinâmica, à análise que Lane (1986, p.94), fez de uma experiência com grupos, apontando como “ ... a dominação se reproduz pela submissão dos membros do grupo", atribuindo poder a um elemento, e, assim, “ “. . reproduzindo relações sociais necessárias para que as contradições não emirjam e nem sejam superadas.” Esta visão determina o papel de coordenador como dono de um saber capaz de interpretar o psíquico oculto de cada indivíduo. Este saber faz do coordenador uma figura de poder que leva os membros ao que se chama "adaptação ativa", sendo que a conscientização passa a ser um processo de autoconhecimento, sem a conotação de um processo de conscientização social.

A coordenação ou liderança do grupo três se caracterizou, basicamente, como "demagógica" (Pichón, 1986, p.113) dado ao discurso contraditório da coordenação que ora discursava sobre a autonomia do sujeito e ora impunha 
as suas vontades ao outro que se submetia. Por outro lado, o grupo se manifestou reforçando o papel da coordenação, o que pressupõe uma identificação profunda com o sedutor comportamento demagógico.

Através dos depoimentos coletados no grupo, constatou-se que a coordenadora era vista como modelo por parte dos participantes. Segundo Pichón (1986, p.130), “ . . o status está relacionado com o prestígio.”, sendo que “. . . o nível é o status, e as características são dadas pelo papel.” Podese dizer que neste grupo de Desenvolvimento Interpessoal, o status da coordenadora estava intimamente ligado ao seu papel competente, sendo que há um aumento de respeito devido a uma identificação da faixa etária do grupo com a da coordenadora. Nos grupos 1 e 2 , jovens coordenavam, o que diminui o status do papel dos coordenadores.

Outra diferença observada nos grupos de Desenvolvimento Interpessoal é que os grupos 1 e 2 se aproximaram mais das “ . . . características de grupo de desenvolvimento interpessoal.” (Castilho, 1995, p.9) não avançando nas questões pessoais, emocionais de cada sujeito, enquanto o grupo 3 se arriscava na análise e interpretações emocionais de cada sujeito.

\section{Grupos de Interesse da UNITI}

\subsection{Grupo 4}

O grupo existe desde 1992. O tema que centra o estudo do grupo foi lançado pela coordenação da UNITI. O grupo contava com onze componentes, sendo que seis integrantes eram os mesmos desde seu início. O grupo estabeleceu como meta à conscientização e informação pessoal e geral quanto ao tema do seu trabalho. Este iniciou sem se preocupar em eleger um coordenador. Entretanto, a instituição UNITI passou a exigir a definição de coordenadores para os grupos de interesse. O grupo se demonstrou resistente para eleger um coordenador. Após a escolha que, na época, foi definida pela competência do coordenador ficou explicitado que o coordenador só iria simbolizar o grupo nas reuniões da UNITI, pois no grupo não haveria hierarquias.

O grupo permitia que cada indivíduo se autorizasse, podendo desenvolver um trabalho referente ao tema estudado para realização de tarefas como: panfletear, colocar matéria no mural ou jornal em nome do grupo. A 
organização e distribuição de tarefas não se faziam a partir de um quadro definido, sendo realizadas conforme o destino da reunião num consenso grupal. Assim, não existia a obediência a regras fixas. No entanto, a UNITI exigia relatórios para controle e averiguações que os grupos de interesse deveriam responder.

Durante o andamento do grupo, a coordenadora desse sentiu-se indisposta a continuar neste papel devido a conflitos com a coordenação da instituição. O grupo como um todo se sentia agredido diante das exigências e críticas da coordenação da UNITI. No segundo semestre, deste grupo, a escolha do coordenador foi feita a partir do acesso político dele junto à coordenação da UNITI, e no primeiro semestre do ano seguinte foi eleita uma nova coordenadora, sendo que a função principal do coordenador, ainda, se concentrava em representar o grupo diante da instituição. $O$ revezamento de coordenadores se fez necessário, pois o grupo encarava este papel como desgastante no enfrentamento com a coordenação da UNITI. Os componentes do grupo sempre aceitavam com resistência a indicação para coordenador, até porque contradizia com a constituição que o grupo se determinava como sem hierarquias.

Este grupo, apesar de ter se encaminhado como "grupo em fusão", definição desenvolvida por Lapassade (1982, p.227), continuava transversalisado pela instituição, estando submetido a uma hierarquia que tentava subverter. Ora era sujeito, autogerenciava-se, ora sujeitado às regras que não admitia dentro do seu funcionamento.

Apesar dos conflitos, o grupo, pareceu estar certo do seu procedimento e satisfeito com sua atuação. Entretanto, no grupo ainda emergiam preocupações quanto a atender as exigências da UNITI, a fim de evitar maiores conflitos. A isto, também, foi associado o sentimento de dívida e, portanto, de obrigação em contribuir com a instituição.

As observações permitiram uma correspondência a seguinte análise desenvolvida por Lane (1986, p.88) onde “ . . . os papéis são desempenhados como naturais, e os indivíduos têm pouca consciência de sua participação no grupo." Foi possível observar a "cristalização de papéis", que significa evitar o comportamento novo que possa levar a um questionamento do grupo e sua 
possível desestruturação - o objetivo é sempre evitar conflitos (Lane, 1986). Assim, o grupo 4 também se caracterizou pela preservação da alienação de seus membros.

\subsection{Grupo 5}

Formado por cinco mulheres, do âmbito da Universidade para a Terceira Idade, que constituíram um grupo de interesse para desenvolver trabalho voluntário de natureza assistencial junto a uma instituição religiosa. Todas aposentadas, sendo a maioria viúvas com poucos filhos, já exerceram, profissionalmente, atividades como professoras, orientadoras educacionais e supervisoras escolares. Tais mulheres foram situadas no extrato social das camadas médias urbanas relativamente estáveis de Porto Alegre, e com idades entre 60 e 70 anos (Almeida, 1998).

$\mathrm{Na}$ instituição religiosa, para a qual prestavam serviços, algumas realizavam trabalhos burocráticos e administrativos (organização da biblioteca, arregimentação), enquanto outras desenvolviam trabalhos de qualificação especializada, como triagem ou atividades de SOE.

O trabalho desenvolvido pelas mulheres do grupo caracterizou-se como um trabalho voluntário pelo qual não recebiam nenhuma remuneração e para o qual se valiam das qualificações que adquiriram ao longo de suas vidas. A autovalorização do próprio grupo em relação aos outros grupos de interesse da UNITI foi observada no discurso do grupo permeado por uma supervalorização do trabalho voluntário dirigido aos deficientes.

Percebeu-se, no território onde as mulheres desenvolviam suas atividades como voluntárias, um prolongamento daquele espaço de atuação e atividade onde elas sempre foram enquadradas como mulheres. A forma como as próprias mulheres definem seu trabalho é de um "trabalho de amor", um trabalho de pessoas amorosas, comprometidas, idôneas, determinadas e capazes. Assim, as atividades desenvolvidas pelas mulheres do grupo corresponderam àquelas representações e atividades articuladas na sua condição de gênero, sendo "o altruísmo e a prestatividade" (Almeida, 1998) valores para os quais as mulheres historicamente e culturalmente foram preparadas. Mas, para além disso, o grupo forneceu "legitimidade a um outro discurso de poder e a outra condição de 
sociabilidade" - "trabalho de mulheres todo poderosas, mães, esposas e trabalhadoras, mulheres ativas ainda na velhice, vividas" - elas rejeitaram estigmas da velhice demonstrando atividade e interesse por causas sociais (Almeida, 1998).

A dinâmica do funcionamento desse grupo, demonstrou uma autonomia em relação à coordenação geral da UNITI, tornando-se relativamente resistente a participações que possam ser configuradas como ingerência em suas atividades internas. O grupo eventualmente realizava reuniões para discutir problemas de âmbito geral, onde se observou um grau também acentuado de auto-suficiência de seus membros individuais. Portanto, este grupo independeu-se da UNITI para o seu funcionamento e organização, porém, sujeitou-se às normas de outra instituição para poder realizar suas atividades.

\subsection{Grupo 6}

Este grupo teve seu começo em 1994, quando contava com a participação de 18 integrantes. Em 1995, este número restringiu-se a oito pessoas, com uma média de participação de cinco a seis pessoas. O grupo realizava uma reunião semanal, com 2 h30min de duração. No início, o grupo tinha uma preocupação com a realização de pesquisas sobre o tema estudado e com o tempo, houve uma priorização das atividades práticas seguidas de debates.

A coordenação era a única função específica no grupo. A escolha da pessoa para exercer esta função se deu por consenso no grupo. Na opinião da coordenadora, estaria faltando um maior comprometimento dos integrantes do grupo com as atividades, pois acabavam elegendo outros compromissos como prioritários, e acreditava que o grupo poderia ter um melhor rendimento se houvesse um pensar sobre as atividades e sobre o próprio grupo. Mas, também, referiu-se a uma maior integração no grupo desde sua criação: "As pessoas estão mais unidas na hora em que temos que resolver algum problema; é uma convivência muito boa, as pessoas estão muito mais próximas”.

Durante os debates, após a atividade prática, os participantes faziam muitas relações da temática discutida com situações do dia-a-dia, e cada um expressava seu ponto de vista. Tal associação permitia maiores possibilidades de aprendizagem. Foi verificado que as variadas visões sobre a prática vinham 
tendo um incremento ao longo dos encontros, com uma participação intensificada dos integrantes. Quanto ao processo de avaliação, não havia nada programado. Antes das reuniões, eram discutidos problemas e a programação para os próximos encontros.

Houveram referências sobre uma dependência do grupo à figura da coordenadora, que muitas vezes se obrigava a adotar uma postura mais diretiva para as atividades. Constatou-se que a maior parte dos integrantes deste grupo manteve uma relação de dependência com a coordenação. Observações sobre a dependência do grupo à figura da coordenação podem indicar uma falta de sistemática reflexão sobre o movimento deste grupo.

\subsection{Grupo 7}

O grupo contava com nove participantes e uma coordenadora. A coordenadora dirigente da aula utilizava técnicas que incluía o aspecto indutivo para o seu trabalho. Ela permitia a produção grupal e incentivava a expressão corporal livre a partir da ordem de improvisação, entretanto procurava conduzir ao resultado que imaginava. Estimulava sempre as alunas dando uma avaliação positiva: "finalizaram bem”; “excelente”. Quanto à auto avaliação das alunas, perguntava o que achavam do seu próprio desempenho. Algumas se avaliavam a partir de terem ou não atingido o que foi pedido pela coordenadora. A coordenadora eventualmente atuava demonstrando o que fazer. Portanto, não se colocava muito como modelo, embora exigisse o aprimoramento e mudança das alunas conforme àquilo que almejava.

Neste grupo a observação foi interrompida a pedido da coordenadora do mesmo por não se sentir bem com tal situação. Segundo Lane (1986, p.95), “ . . . a não neutralidade do observador e a sua interferência no processo grupal provoca uma maior produtividade do grupo ou o caráter perturbador do observador, exigindo dele um compromisso de sigilo e de participação no grupo." Pichón (1986, p.114), define “. . . a conspiração como uma situação constante e latente em todo o grupo social que se manifesta como incerteza grupal e aumento de insegurança, tornando o grupo - no aqui e agora da tarefa - muito frágil." No caso, deste grupo, o observador parece ter abalado a neutralidade do grupo, além de personificar como um bode expiatório à situação de conspi- 
ração. O grupo apresentou-se como cristalizado e resistente a qualquer intervenção que pudesse questionar a sua trajetória. A liderança caracterizou-se como autoritária, na sua essência.

\section{Grupo 8 (Grande Grupo = Grupão)}

O Grupo 8 representou o total dos alunos da UNITI reunidos, formando um grupo singular, com objetivos próprios e dinâmica bem diversa dado ao número elevado de participantes. A equipe coordenadora esteve composta por profissionais, estagiários e bolsistas de psicologia, tendo uma coordenadora principal que dirigia o trabalho no "Grupão".

Geralmente, este grupo se movimentou como grupo "serializado" conceito desenvolvido por (Lapassade, 1982, p.227) desde a sua disposição num auditório com cadeiras enfileiradas até a dificuldade da intercomunicação num grupo que se caracterizou como massa. No entanto, a coordenação da UNITI, esporadicamente, proporcionava situações onde se fazia necessário o empenho de todos os participantes para a realização de tarefas, como por exemplo, dividindo este grande grupo em grupos menores, a fim de que houvesse uma interação de seus membros, tornando-os produtores de determinado trabalho que depois seria apresentado para o grande grupo. Nestas ocasiões, o Grupão transitou da sua serialidade característica, em assistir, para uma dinâmica de trocas de opiniões e saberes tornando-se assistentes da produção do Grupão.

Observou-se, como resultados obtidos durante o desenvolvimento do trabalho no grande grupo, um aumento da autonomia dos alunos, com um crescente envolvimento nas atividades grupais e um reconhecimento, por parte do grupo, do valor dos trabalhos produzidos (Vargas, 1996).

Contudo, mesmo com a proposta, da UNITI, de intervenção psicossocial para reconstruir um modo de relação grupal mais participativo e menos centrado em determinadas pessoas, observou-se que, por vezes, a própria coordenação da instituição entrou num jogo contraditório, atendendo o apelo do grupo por um dirigente com maior poder decisório. Assim, tal dirigente pode carregar a maior responsabilidade tanto pelo sucesso como pelo fracasso dos resultados.

Foucault (1989), coloca que a luta contra as formas de sujeição - 
contra a submissão da subjetividade - está se tornando cada vez mais importante, mesmo que as lutas contra as formas de dominação e exploração não tenham desaparecido. E define a "microfísica do poder" como “ . . . uma complexa rede aplicada sobre o corpo como estratégia de dominação através de disposições táticas" (Foucault, 1992, p. 244). Atualmente, a luta do movimento dos idosos centra-se na não submissão às normas sociais que colocam o velho a margem da sociedade: lutam pela reconquista da cidadania, do respeito, deixando de serem integralmente sujeitados. Os dados obtidos nas observações, no microcosmo da UNITI, permitiram verificar a dificuldade da luta contra a submissão da subjetividade, pois a eliminação de opressão social vai além do ambiente externo dominador. O subjetivo do sujeito está impregnado pela opressão e ele projeta e promove um ambiente dominador dificultando o seu comportamento auto-suficiente.

A instituição à qual o grupo pertence, um chefe, por exemplo, pode ser quem veicula a ideologia da instituição no grupo. Isso foi claramente verificado no grande grupo onde a coordenadora veiculava a ideologia que estimulava o trabalho nos subgrupos. O seu papel de pessoa competente e seu status de experiente e idosa reforçaram o poder que o grupo lhe delega.

Pichón (1988), define como vínculo a esse conjunto que se estabelece sempre em função de outros vínculos condicionados historicamente no sujeito e que, acumulados constituem o que denominamos inconsciente, por isso, à idéia de um papel individual, temos de agregar o conceito de papel do vínculo configurando uma estrutura social mais integrada que agrupa indivíduos e estabelece relações entrecruzadas, constituindo um vínculo estreito em função de uma determinada ideologia. Este vínculo é ideológico e condiciona neles a existência de uma estrutura como totalidade, que começa a funcionar como um grupo, com uma dada ideologia e uma operatividade determinada, estabelecendo vínculos com outros grupos sociais. Neste sentido, podemos dizer que a UNITI também participa do grupo de expressão dos idosos e busca desbancar o estereótipo da velhice insuflando as suas ideologias nesse público que se identifica e passa a defender a mesma bandeira.

\section{Correlações Finais}


Observou-se nestes grupos a diferença dos fins, objetivos e modos de funcionamento. Alguns tiveram um papel não definido de líder para determinado sujeito, como nos grupos 4 e 5, onde o poder foi distribuído conforme o compromisso de cada um com as tarefas. Noutros o papel de liderança estava centrado num sujeito que detinha o saber e decidia, pois o valor da sua definição tinha mais valor que a dos outros. O grupo 7 exemplificou bem o papel de liderança centrado num sujeito, provavelmente sem a coordenadora este grupo se extinguiria.

Nos grupos onde a proposta de relacionamento foi de igualdade entre os membros detectou-se a dominação pela submissão dos membros a outra pessoa. Assim, nos grupos 1, 2 e 6, apareceu a questão da maior responsabilidade para o coordenador: essa posição vai além de representar o grupo, é representar o que há de melhor no grupo.

Apesar do discurso de autogestão, como no grupo 4 ou a independência no grupo 5 ser enfatizada, identificou-se uma demanda no interior dos grupos em subjugar-se a ordens superiores, sendo percebida uma ânsia pelo reconhecimento da instituição valorizando o grupo.

Considerou-se aqui a questão de gênero desta geração onde se identifica um papel estereotipado específico da mulher e, portanto, um papel submisso correspondendo às determinações culturais de uma época ultrapassada, mas que continua determinista nas suas vidas. Pois, mesmo com as mudanças sócio-econômicas ocorridas no país ao final da $2^{\mathrm{a}}$ Guerra Mundial, como o aumento das possibilidades educacionais para as mulheres e sua crescente inserção no mercado de trabalho, o casamento mantinha fundamental importância na vida da mulher dos anos 50, percebendo-se a cristalização da distinção entre os papéis masculinos e femininos (Bassanezi, 1997) que preservava as qualidades femininas herdadas do início desse século: pureza, resignação, instinto materno e passividade (Lopes, 1993). Pelo fato dos grupos estudados terem se constituído por uma maioria de mulheres, pertencendo a uma geração anterior aos anos 40, onde o papel social da mulher era baseado na sua submissão, torna-se difícil uma mudança radical de atitudes, mesmo que, nos dias de hoje, a sociedade autorize uma liberdade que era inconcebível há 20 anos atrás.

Portanto, as questões de diferenças de gênero relativas ao comporta- 
mento de homens e mulheres persistem nos dias de hoje. Debert (1988) observa, através de uma pesquisa com 30 homens e 45 mulheres com mais de 70 anos, a experiência diferenciada sobre o envelhecimento entre os sexos: as mulheres vivem a sua velhice como sendo de maior liberdade em oposição a sua juventude quando foram vítimas de maior opressão social, conseqüentemente ocorre uma visão mais positiva do envelhecimento feminino, enquanto, para os homens a experiência positiva na vivência do envelhecimento esta principalmente vinculada ao poder econômico. Talvez, por isso, "a luta pelos direitos do cidadão e pela redistribuição da riqueza mobiliza sobretudo um público masculino, enquanto a luta por mudanças culturais mais amplas - movimentos sociais - mobiliza sobretudo as mulheres de mais idade" (Debert, 1994, p.36)

Sendo que o poder se dá inclusive por submissão, ora um se submete, ora outro se submete à razão ou à autoridade do outro, considerou-se que a geração destes grupos pesquisados se submetia mais pelo autoritarismo. Bosi (1987, p.11), fala em "memória do hábito" onde “. . o corpo guarda esquemas de comportamento de que se vale automaticamente na sua ação sobre as coisas." - este processo estaria vinculado às exigências de socialização, sendo que a “memória hábito faz parte de todo o nosso adestramento cultural". Não podemos separar a situação atual do velho de sua história de vida, de uma construção baseada em preceitos de uma época, que vai além da influência dos valores sociais, isto é, uma construção de emoções e sentimentos que estão enraizados muito mais na sua história. Entretanto, agora, estes idosos, apesar de concordarem buscar se libertar das suas antigas amarras, a maioria espera alguém que venha demovê-los. As marcas da cultura imposta pelo autoritarismo determinista desta geração, carregadas de "certos" e de "errados", tornaram-se nós que as mudanças de valores sociais, a liberdade de expressão, não conseguiram desfazer na maioria destas pessoas que chegaram na UNITI como se viessem do túnel do tempo, deslocadas da atualidade e sobrecarregadas de conflitos existenciais.

Assim, a investigação nestes grupos permitiu verificar que em geral os sujeitos, desta pesquisa, costumam reivindicar um líder mais autocrático. Mesmo havendo nos grupos da UNITI líderes que assumem determinados trabalhos, percebeu-se uma tendência ao autoritarismo que é alimentada pela 
submissão geral do grupo que concede poder atuante e, conseqüentemente, decisório para o líder. Somente uma minoria dos sujeitos se identificou com uma liderança democrática e partilhada. Mesmo quando os coordenadores dos grupos estimulavam e propiciavam condições para o grupo exercer a sua autonomia, constatou-se uma certa resistência, pois havia solicitações de uma técnica mais diretiva do coordenador. Portanto, a tendência é que as pessoas desta faixa etária mantenham vínculos de dependência onde são mais sujeitadas do que sujeitos. Preferem ficar com o poder de conceder o poder ao outro e, assim, responsabiliza-lo pelas ações. Acrescenta-se, ainda, o fato do poder utilizado pela mulher se identificar com a posição subordinada. Perelberg (1992) define como o poder da frágil, neste sentido, no campo onde ela é restringida, exerce seu poder com ou sem autoridade.

Paulatinamente, as instituições universitárias que foram pioneiras no atendimento educacional à velhice “. . . deverão refletir sobre as suas práticas e com isso, gerar modelos e princípios de atuação para serem reaplicados, aperfeiçoados e fundamentados, dentro de um estilo brasileiro de educar adultos." (Neri; Cachioni, 1999, p.129). A partir disso, propõe-se uma análise permanente das dinâmicas dos grupos de idosos, a fim de promover um aumento da consciência destes sujeitos nas relações de poder no interior dos grupos e entre os grupos, através de uma intervenção de ordem psicossocial que permita um processo de aprendizagem mais atuante deste idoso na relação grupal.

\section{Referências}

1 ALMEIDA, H. D. Trabalho Voluntário: estruturas herdadas e sucessões transformadoras na construção da identidade social. In: CASTRO, O.P. (Org.). Velhice que Idade é Esta? uma construção psicossocial do envelhecimento. Porto Alegre: Síntese, 1998.

2 BARDIN, L. Análises do Conteúdo. Lisboa: Edições 70, 1979.

3 BAREMBLITH, G. Compêndio de Análise Institucional. Rio de Janeiro: Rosa dos Tempos, 1992.

4 BASSANEZI, C. Mulheres dos Anos Dourados. In: DEL PIORI, M. (Org.). História das Mulheres no Brasil. São Paulo: Contexto, 1997. 
5 BOSI, E. Memória e Sociedade: lembranças de velhos. São Paulo: Queiroz, 1987.

6 BROWNING, C.J. Late-life Education and Learning: the role of cognitive factors. Educational Gerontology. n.21, p.401-413, 1995.

7 CASTILHO, A. A Dinâmica do Trabalho de Grupo. Rio de Janeiro: Qualitymark, 1995.

8 DEBERT, G.G. Envelhecimento e Representação da Velhice. Revista Ciência Hoje, Rio de Janeiro: v.8, n.44, jul. 1988.

9 DEBERT, G.G. Gênero e Envelhecimento. Estudos Feministas, Porto Alegre: v.2, n.3, 1994

10 FOUCAULT, M. Microfísica do Poder. Rio de Janeiro: Graal, 1992.

11 FOUCAULT, M. Vigiar e Punir. Petrópolis: Vozes, 1989.

12 HAGEMANN, L.; PINHAL, M. A.; SILVA, M. S.; CARLOS, S. A. A

Teoria Psicológica de Kurt Lewin. Porto Alegre: Cursos de Pós Graduação em Educação, UFRGS, 1977.

13 LAPASSADE, G. Grupos, Organizações e Instituições. Rio de Janeiro: Francisco Alves, 1982.

14 LANE, S. et al. Psicologia Social: o homem em movimento. São Paulo, Brasiliense, 1986.

15 LEHR, U. La Desinsertion des Persones Agees. In: Conferência Internacional de Gerontologia Social, $11^{\circ}$, 1984, Roma.

16 LOPES, G. Sexualidade Humana. Rio de Janeiro: Nova Fronteira, 1993.

17 MEDINA, M. F. Um Estudo sobre Autogestão. Monografia (Conclusão de estágio de Psicologia Escolar) - Curso de Psicologia, UNITI - UFRGS, Porto Alegre, 1992.

18 NERI, A. L.; CACHIONI, M. Velhice Bem Sucedida e Educação. In: DEBERT, G.G.; NERI, A.L. (Orgs.). Velhice e Sociedade. Campinas: Papirus, 1999.

19 PERELBERG, R.J. Equality, Asymmetry and Diversity: on Conceptualizations of Gender. In: PERELBERG, R.J.; MILLER, A.C. (Orgs.). Gender and Power in Families. London: Routledge, 1992.

20 PICHÓN-RIVIÈRE, E. O Processo Grupal. São Paulo: Martins Fontes, 1986. 
21 PICHÓN-RIVIÈRE, E. Teoria do Vínculo. São Paulo: Martins Fontes, 1988

22 SALGADO, M. A. Gerontologia Social. Rio de Janeiro: CBCISS n.150, 1979.

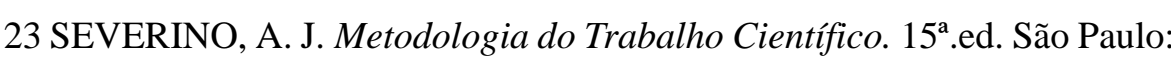
Cortez Autores Associados, 1989.

24 TERRA, A. P.; SILVA, J. C. Uma Proposta de Trabalho com Grupos de Terceira Idade. Monografia (Conclusão de estágio de Psicologia do Trabalho) Curso de Psicologia, UNITI - UFRGS, Porto Alegre, 1992.

25 VARGAS, L. V. O Idoso e o Vínculo Institucional. Relato de pesquisa/ FAPERGS, não publicado, Porto Alegre: UNITI - UFRGS/FAPERGS, 1996. 